\title{
Hubungan Antara Kualitas Ibadah Shalat Dengan Keharmonisan Keluarga
}

\author{
Diah Auliani ${ }^{1}$, Aida Arini ${ }^{2}$ \\ 1,2 Pendidikan Agama Islam, Fakultas Pendidikan Agama Islam, Universitas Hasyim Asy'ari, Jombang
}

\begin{tabular}{|c|c|}
\hline Article Info & ABSTRACT \\
\hline Article history: & Praying is something that is done with special words and actions that begin \\
\hline Received Apr 17, 2020 & $\begin{array}{l}\text { with intention. prayer has the obligatory requirements of Islam, } \\
\text { understanding, age, not being menstruated, not handicapped. The family is an }\end{array}$ \\
\hline Accepted Aug 3, 2020 & $\begin{array}{l}\text { institution that exists in the community, which can determine harmony in the } \\
\text { community so that the community is very dependent on happiness in the }\end{array}$ \\
\hline Keywords: & $\begin{array}{l}\text { marriage. A harmonious family can determine the level of community } \\
\text { welfare, because marriage is highly recommended by Islam for those who }\end{array}$ \\
\hline Quality of Prayers & have been able and meet the conditions. The objectives of the researcher are \\
\hline Family Harmonism & (1) to describe the quality of prayer worship in Tebuireng Gg Village 1. (2) \\
\hline Islamic Education & $\begin{array}{l}\text { To describe the harmony of the family in Tebuireng Gg Village } 1 \text {. (3) To } \\
\text { describe the relationship between family harmony with the quality of prayer } \\
\text { in Tebuireng Gg } 1 \text { village. The research that will be used is a descriptive } \\
\text { quantitative expost facto approach that is correlative. The independent and } \\
\text { related variables in this study include the Quality of Prayers (X) and Family } \\
\text { Harmony (Y). This research was conducted in Tebuireng Gg } 1 \text { Hamlet in } \\
\text { January-February 2019. The data collection used questionnaires and } \\
\text { documentation distributed to each family. Date analysis techniques using } \\
\text { hypothesis testing. }\end{array}$ \\
\hline
\end{tabular}

This is an open access article under the CC BY-SA license.

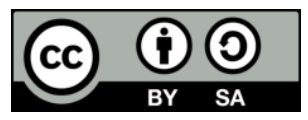

\section{Corresponding Author:}

Diah Auliani, Aida Arini

Pendidikan Agama Islam, Fakultas Pendidikan Agama Islam,

Universitas Hasyim Asy'ari,

Email: Diahauliani@gmail.com, azhaapink@gmail.com

\section{PENDAHULUAN}

Ibadah secara etimologi berasal dari bahasa Arab yang artinya melayani, tunduk, patuh dalam segala yang di anjurkan oleh Allah SWT, sedangkan menurut pendapat lain ibadah adalah semua yang dilakukan dengan tujuan kebaikan dan mendapatkan apa yang telah kita perbuat di dunia. (Amin Syukur. 2003:80). Dalam Al-Quran surat Al-Baqarah ayat 45 di jelaskan bahwa shalat adalah sebagai penolong manusia di akhirat kelak.

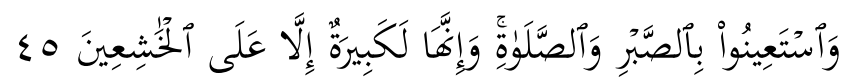

"Jadikanlah sabar dan shalat sebagai penolongmu. Dan sesungguhnya yang demeikian itu sungguh berat, kecuali bagi orang-orang yang khyusyu'

Ibadah Shalat merupakan ibadah paling pertama dilakukan sebelum ibadah lain. Keagungan shalat seorang hamba hanyalah karena menghadapkan dirinya lahir batin pada Allah. Seseorang menyerahkan diri kepada orang lain dan mempunyai niat kebencian tidak dinamakan, orang yang beribadah dan ada juga orang yang cinta kepada sesuatu tetapi tidak patuh kepadanya, contoh seperti orang yang mencintai anak atau suaminya. Rahman dan zainuddin (2002: 4). Macam-macam ibadah dibagi menjadi dua menurut Rahma dan Zainuddin (2002: 88) Di sini ada beberapa Macam ibadah, ibadah dibagi menjadi 
dua bagian pertama segi ruang lingkup, yang kedua dilihat dari segi bentuk dan sifatnya, dalam hal ini dijelaskan sebagai berikut Segi ruang lingkupnya ,Segi bentuk dan sifatnya

Menurut Rahman dan zainuddin (2002:90) Ibadah memiliki tujuan yang utama yaitu berserah diri kepada Allah dan selalu rendah hati dalam niat kepadanya dalam situasi apapu mau senang atau susah. Dengan tujuan ini seseorang akan mencapai sesuatu yang tinggi di akhirat. Shalat contohnya, disayariatkan pada dasarnya mempunyai tujuan untuk berserah diri kepada Allah SWT dengan sangat ikhlas.

Selain itu juga menghindarkan diri dari kemungkaran dan kekejian masih banyak tujuan lain yang dapat diwujudkan melalui ibadah shalat, seperti beristirahat dari kesibukan dunia, membantu dalam memenuhi kebutuhan, membawa seseorang masuk surge dan menjauhkan diri dari api neraka.

Shalat juga mempunyai syarat yaitu syarat yang pertama Islam karena shalat wajib bagi orang muslim dan tidak wajib bagi orang yang non muslim. Yang kedua ialah berakal shalat tidak wajib bagi orang gila, orang yang tidak berakal karena wajinya shalat ialah berakal dan tidak mengalami gangguangangguan seperti diatas. Yang ketiga ialah baligh shalat tidak wajib bagi bayi sebelum dia baligh. Dalam buku Abdul Qadir( 2011: 188)

Rahman Ritonga dan Zainuddin (1997:87) Ibadah Shalat ditetapkan dan disepakati umat sejak zaman Nabi dahulu sampai sekarang menyatakan, bawa kewajiban shalat lima waktu sehari semalam. Tidak ada suatu bantahan dari kaum muslimin terhadap kewajiban ini. Shalat yang lain tidak ada yang diwajibkan keculai shalat yang ditentukan. Oleh karena itu ibadah shalat adalah rukun islam yang kita ketahui dan kita percaya.

Dalam al-Qur'an surat At-Tahrim ayat 6 di sini menjelaskan bahwa kita di anjurkan untuk pelihara dirimu dan keluargamu agar terjauh dari apa neraka. Keharmonisan keluarga yaitu keluarga yang mempunyai waktu untuk anggota keluarganya, selalu memberikan arahan yang baik untuk anggota keluarganya, dan saling memberikan nasehat yang berguna untuk keluarga, saling memberikan penghargan yang telah dicapai selama itu dalam hal positif, saling pemaaf, serta tolong menolong dalam kebijakan, memiliki semangat kerja yang baik, baik dengan tentangga dan saling menghormati, selalu taat mengerjakan ibadah, memiliki rasa hormat pada yang lebih tua, dan selalu mencintai ilmu pengetahuan. Sofyan S. Willis (2011: 15-16).

Keluarga adalah rumah bagi anggota keluarganya apabila rumah itu indah maka yang menempati juga akan merasakan keindahanya itu dan apabaila sebaliknya rumah itu tidak ada keindahan maka yang menempati juga merasakn tidak ada keindahan yang dirasakan di dalam suatu rumah tangga, ayah dan ibu sebagai anggota keluarga yang sangat berperan penting bagi keluarga kecilnya. Anggota keluarga sangat berpengaruh besar terhadap lingungan sekitarnya dianatranya lingkungan masyarakat.

Menurut Safrudin Aziz (2015:15). Berkomunikasi dalam rumah tangga itu sangat penting karna komunikasi membuat kita mengerti apa yang dikerjakan oleh istri dan sebaliknya apa yang dikerjakan oleh suami. Dengan itu keharmonisan akan muncul dalam rumah tangga Keluarga merupakan lembaga terkecil dalam masyarakat. Keluarga terbentuk melalui sebuah perkawinan.

Keluarga pada dasarnya memiliki berbagai macam fungsi baik secara ekonomi, sosial, pendidikan, psikologis, hukum dan fungsi lainya. Fungsi ekonomi berarti keluarga yang mengelolah semua tentang perekonomian keluarga . pengahasilan dan pengeluaran dapat tersusun dan terencana dengan baik. Dalam Fungsi sosial keluarga sebagai orang yang selalu meberikan motivator kepada anggota keluarganya agar bisa besikap baik dengan orang lain dalam proses menjalin hubungan yang erat baik dalam satu keluarga ataupun dengan masyarakat lain.

Keluarga adalah sebuah ikatan perkawinan antara suami-istri, dalam rumah tangga pastinya mempunyai buah hati atau seoranga anak yang di cintai, pertengkaran dalam rumah tangga sangatlah wajar terjadi namun apabila salah satu dari mereka ada yang mengalah pastinya keluarga tidak akan mengalami pertengkaran dan adanya sebuah perceraian. Saling memahami kunci dari keluarga yang haromins dan kelurga yang bahagia. Safrudin Aziz (2015: 15)

Dalam pendidikan Islam di lingkungan keluarga materi yang diberikan yang tidak diajarkan di sekolahan tentang menjalankan ibadah shalat dan berakhlak baik kepada yang lebih tua. Dan Begitu juga dengan fungsi psikologis, bahwa keluarga memiliki pengaruh tinggi terhadap tumbuh kembang anaknya. Bila orang tua menerapkan pola asuh keras maka anak juga akan berkarakter keras, dan sebaliknya jika orag tuanya menerapkan kasih sayang jiwa yang ramah anak juga akan mengikuti seperti yang di ajarkan orang tua. Safrudin Aziz (2015: 19-19)

Menurut Hasan Basri (2004:135). Sebagai keluarga tidaklah selalu dalam damai dan tenang perkembanganya. Dalam keluarga juga sering tertimpa masalah dan salah paham kemudian datang mengahampiri, menggoncang dan menguji taraf ketahanan badan dan mental para pendirinya. Dan Ada juga yang tidak tahan melalui berbagai gelombang ombak dan badai dalam sebuah rumah tangga, sehingga keluarga itu berantakan dan hancur dalam perceraianyang yang sangat menyakitkan

Di sini ada beberapa syarat kelurga yang harmonis Zakiyah Daradjat, (2011:61) Di sini ada beberapa 
syarat kelurga yang harmonis, Persyaratan dalam mencapai keluarga harmonis, diantarnya adalah: saling menerima antara suami dan istri, saling mengerti, menghargai, mempercayai dan saling mencintai.

Menurut Meichiati, (2004: 61). Faktor keluarga harmonis yang dapat meningkatkan kebahagian dalam rumah tangga adalah

Menciptakan kehidupan beragama dalam keluarga. Dalam keluarga ibadah sangatlah berperan penting dalam mempengaruhi kehidupan yang telah di jalani, karena agama sebuah tiang dalam kehidupan. Agar keluarga itu dapat beretika dengan baik, berahlak dan mempunyai moral yang tinggi.

Mempunyai waktu bersama keluarga. Waktu tidak akan pernah terulang lagi dan janganlah sampai melewatkan waktu tersebut dengan hal-hal yang tidak penting, waktu bersama keluarga dan kerabat sangatlah penting dalam sebuah kehidupan, bisa dikatakan keluarga harmonis ialah luangkan waktu untuk berkumpul walaupun hanya minum teh, makan, dan bercerita tentang hal yang dilakukan selama sehari.

Mempunyai komunikasi yang baik antara keluarga. Komunikasi dalam keluarga dapat mencipakan sebuah keluarga yang harmonis karena komunikasi sangatlah penting. Berkomunikasi dengan anak yang sudah dewasa juga merupakan hal yang penting karena sebagai orang tua tidaklah mengetahui apa yang dilakukan selama diluar rumah.

Saling meghargai antara keluarga. Saling menghargai antara anggota keluarga, tentang pendapat atau apaun yang telah mereka pilih sebaiknya sebagai anggota saling menghargai beberapa pendapat anggota keluarga yang lainyan agar tetap terjaga kerukunan yang telah terjaga selama ini.

Keempat aspek tersebut sangatlah berhubungan dengan satu dan yang lainya. Kebahagian dalam rumah tangga di tentukan dari beberapa aspek yang sudah di bahas di atas. Untuk menciptakan kelurga yang harmonis fungsi orang tua sangatlah menentukan tumbuh kembang anak dan kebahagian anak dalam kehidupanya kelak dalam lingkungan keluarga maupun lingkungan masyarakat luas.

\section{METODE}

Menurut Sugiyono (2016:7) Metode penelitian kuantitatif yaitu metode yang dapat dikembangkan sebagai penelitian baru. Metode kuantitatif karena penelitiannya berupa nilai dan analisis nya menggunakan statistik. Penelitian kuantitatif ialah proses mencari permasalahan-permasalahan di sekitar kita dengan menggunakan pendekatan yang sama dengan apa yang telah terjadi di lingkungan sekitar seperti contoh" keharmonisan keluarga dengan kualitas ibadah shalat " karena antara keluarga dengan ibadah shalat sangat berkaitan dengan adanya keluarga harmonis keluarga saling memahami antara anggota keluarga dengan yang lain menjadikanya saling memahami.

Penelitian ini melakukan beberapa tahapan penelitian ialah observasi, dokumentasi sebagai berikut:

Observasi Menurut Sutriso Hadi mengemukakan bahwa suatu proses yang tersusun dalam suatu perlilaku manusia, contohnya proses kerja, perilaku manusia gejala alam. Angket Adalah data yang dapat dilakukan dengan menggunakan Metode Kuesioner (Angket). Angket merupakan bentuk pengumpulan data yang bisa dilakukan dengan cara menyebarkan pertanyaan kepada responden.

Dokumentasi digunakan untuk mengambarkan keadaan yang telah terjadi. Dokumentasi bisa berbentuk gambar, tulisan atau karya-karya dari seseoran. Selain itu dokumentasi juga digunakan untuk mengetahui jumlah dan daftar nama responden dan kk perkeluarga. Deni Darmawan,(2016: 166) Teknis analisis fakta yang akan digunakan oleh peneliti beserta alasannya. Alasan ini akan dikaitakan dengan perumusan masalah penelitian, tujuan penelitian, sifat data, dan yang penting adalah dikaitkan dengan kemampuan peneliti, baik kamampuan akademis, keuangan, maupun waktu yang tersedia serta analisi statistik yang dibutuhkan. Analisis data ialah proses penyususan secara manual data yang diperoleh dengan wawancara, lapangan, dan angket, dengan mengorganisasikan data kedalam katagori dan membuat kesimpulan untuk pemahaman penulis dan pembaca.

\section{HASIL DAN PEMBAHASAN}

Tebuireng dahulunya merupkan nama dari sebuah dusun yang masuk wilayah ckir, kcamatan diwak, kabupaten Jobang di dirikan pada tahun 1899 menurut penuturan masyarakat sekitar tebuireng berasal dari "kebo ireng " yang dalam bahasa Indnesia berarti kerbau hitam. Konon, ada seorang peduduk yang mimiliki kerbau berkulit kuniug, suatu hari, kerbau tersebut menghilang dan setelah dicari, kerbau itu ditemukan sudah berwarna hitum. Kerbau itu hampir mati, tubuhnya panuh lintah karena terperosok di rawa-rawa yang penuh lintah dan lumpur, dan sang pemilik berteriak "kebo ireng! Kebo ireng!" sejak saat itu, dusun tempat ditemyukanya kerbau itu dikenal dengan nama kebo ireng.

Pada perkembangan selanjuttnya, ketikaa penduduk dusun tersebut mulai ramai, nama kebo ireng berubah menjadi Tebuireng. Tidak diketahui dengan pasti kalaupun perubahan itu terjadi dan apakah hal itu ada kaitananya dengan muncul pabrik gula di selantan dusun tersebut, yang banyak mendoronng masyarakat untuk menanam tebu, ada kemungkinan karena tebu yang ditanam berwarna hitam maka 
dusun berubah nama menjadi dusun Tebuireng

Pada penghujung abad ke-19, disetkitar Tebuireneg bermunculan pabrik-pabrik milik oerang asing, terutaama pabrik gula, sekilas keberadaan pabrik itu menguntungkan warga setempat karena banyaknya lanpangan pekerjaan yang dibuka, tapi sebenernya pabrik itu merugikan warga dari aspek psikologis. Masyarakat belum terbiasa menerima upah sebagai buruh, sehingga uang tersebut lebih banyak digunakan dalam hal seperti judi dan mabuk. Ketergantungan masyarakat terhadap hal itu membuat mereka berbongdong-bondong menjuael tanah meereka. Lambat laun penduduk semagin banyak menempati dusun yang didirikan oleh kh hasyim asyari dan kemudian dusun tebuireng terbagi menjadi beberapa Gg yaitu Gg 1 sampai G5. Dalam hal ini penelitian saya mengambil Gg1 untuk melakukan penelitian dan pengambilan data.

Uji validitas data pada semua butir instrument yang digunakan dalam penelitian ini menggunakan analsisis korelasi Product Moment dengan taraf signifikan 0,05 (5\%). Sedangkan reabilitas merupankan uji yang digunakan dalam pengukuran ulang. Hasil uji reabilitas dinyatakan reliabel jika nilai cronbach's alphae $<0,60(60 \%)$. Hasil uji validitas butir instrumen penelitian berupa angket diperoleh dengan menganalisis jawaban responden dengan menggnunakan analisis korelasi Prouduct Moment dalam program SPSS < 16.0 for Windows yang terpasang dalam komputer. Berdasarkan lampiran mengenai hasil perhitungan uji validitas instrument angket dan uji reliabelitas.

Dari 15 item pernyataan, setelah diujikan melalui validitas dengan program SPSS < 16.0 for Windows untuk Variabel Kualitas Ibadah Shalat (X) semua item dinyataan valid. Data yang akan di sajikan dalam penelitian ini adalah untuk memberikan gambaran secara umum data yang diperoleh dilapangan. Data yang didapat berupa data mentah yang diolah menggunakan teknik statistik desekripsi. Adapun data yang disajikan berupa hasil tabulasi sekor dari setiap angket yang disebar dilapangan dan distribusi frekuensi beserta prosentase setiap variabel. Berdasarkan judul dan perumusan masalah di sini ada dua variabel bebas dan variabel terkait, yaitu meliputi data tentang kualitas ibadah shalat (X) keharmonisan keluarga (Y) sampel data dalam penelitian ini $20 \mathrm{kk}$ (Kartu keluarga). Penjeelasan dari masing-masing variabel berdasarkan hasil penyebaran kuesioner tersebut hasilnya dijelaskan sebagaimana dibawah ini.

Uji Hepotesis. Setelah melakukan penelitian dan mendapatkan hasilnya maka tahap selanjutnya adalah pengujian hipotesis. Adapun untuk menguji hipotesis maka diperlukan langkah-langkah sebagai berikut: Menentukan hipotesis. Hipotesis alterntatif (Ha) adalah "Terdapat hubungan antara keharmonisan keluarga dengan kualitas ibadah shalat Dusun Tebuireng Gg 1". Hipotesis Nol ( Ho) adalah "tidak terdapat hubungan antara keharmonisan keluarga dengan kualitas ibadah shalat dusun Tebuireng Gg 1"

Menentukan taraf signifikan (a). Peneliti disini dalam meneliti sebuah rumah tangga dengan itu menggunakan taraf signifinkan sebesrar $5 \%$ atau 0,05 dengan nilai kebenaran sebesar 95\% atau 0,95. Mententukan kriteria pengujian hipotesis. Kriteria pengujian dilakukan untuk mengetahui apakah hipotesis alternatif (Ha) diterima atau ditolak ataukah sebaliknya hipotesis Nol (Ho) diterima atau ditolak. Adapun kreteria pengujian hipotesis adalah sebagai berikut:

- Ha diterima apabila $\mathrm{r}$ hitung/ $\mathrm{t}$ hitung > dari $\mathrm{r}$ table / $\mathrm{t}$ table, dengan demikian maka Ho ditolak.

- Ho diterima apabila $\mathrm{r}$ hitung/ $\mathrm{t}$ hitrung < dari $\mathrm{r}$ table/ $\mathrm{t}$ table, dengan demikian maka Ha ditolak

Melakukan perhitungan. Dalam pengujian hubungan, peneliti melakukan uji statistik yaitu uji regresi. Sebelum menganalisis data, peneliti menggunakan rumus regresi linear, oleh karena itu perlu dijabarkan terlebih dahulu mengenai korelasi atau ada tidaknya hubungan antara variabel-variabel tersebut.

\section{KESIMPULAN}

Berdasarkan tabel dan hasil dari data tentang keharmonisan keluarga dapat dikemukakan bahwa dari 20 responden, menunjukan sangat harmonis dengan frekuensi 15 prosentase $75 \%$ dan kategori cukup harmonis dengan frekuensi 5 prosentase 25\%, sedangkan kurang harmonis dengan frekuensi 0 prosentase $0 \%$ dan keluarga di dusun Tebuireng tergolong sangat harmonis.

Berdasarkan tabel dan hasil perhitungan analisis tentang kualitas ibadah shalat dapat dikemukakan bahwa dari 20 responden, menunjukan sangat berkualitas ibadah shalat dengan frekuensi 19 prosentase 95\% dan kategori cukup berkualitas ibadah shalat dengan frekuensi 1 prosentase 5\%, sedangkan kurang berkualitas ibadah shalat dengan frekuensi 0 prosentase $0 \%$ dan ibadah shalat dusun Tebuireng tergolong sangat berkualitas.

Dari hasil analisis yang telah dilakukan maka dapat disimpulkan bahwa ada Hubungan antara variabel keharmonisan keluarga dengan kualitas ibadah shalat, dapat dilihat dari angka probabilitas (sig) sebesar 0,009 yang lebih kecil dari 0,05 ketentuan mengatakan jika angka probabilitas 0,05 maka hipotesis alternatif diterima sehingga terdapat hubungan yang poseitif dan sigenifikan antara keharmonisan keluarga dengan kualitas ibadah shalat. 


\section{REFERENSI}

Alim, Muhammad. Pendidkan Agama Islam, Bandung: PT. Remaja rosdakrya, 2006.

Arikunto, suharsimi. prosedur penelitan sutatu pendekatan praktis. Jakarta: Renika Cipta. 2010.

Aziz. Ali. 60 Menit Terapi Solat Bahagia. Surabaya: Pt. Duta Askara Mulia, 2013

Basri Hasan. Merawat Cinta Kasih, Yogyakarta: Pustaka Pelajar Offset, 2004.

Daradjat, Zaykiyah. Ilmu Pendidikan Islam, Jakarta: Bumi Askara, 2011.

Daremawan, Deni. Metode Penelitian Kuantitatif. Bandung: Rosdakarya, 2016

Depdikbud, Kamus Besar Indoenesia, Jakarta: Balai Pustaka, 1989.

Hasan, Muhammad Tholhah. Dinamika Pemikiran tentang Pendidikan Islam. Jakarta: Tantabora Press, 2006.

Meichiati. Membeangun Keharmonisan Keluarga, Bandung: Alfabeta, 2004.

Qadir, Abdul. Fiqih Shalat Empat Madzhab. Yogyakarta: Hikam Pustaka. 2011.

Rahman, Ritonga dan Zainuddin. Fiqih Ibadah. Jakarta : Gaya Media Pratama. 2002.

Safrudin, Aziz. Pendidikan Keluarga (Konsep dan Strategi), Yogyakarta: Gava Media, 2015

Sochib, Muhammad. Pola Asuh Orang Tua dalam Membantu Anak Mengembangkan Disiplin Diri. Jakarta: Riyneka Cipta, 1998.

Sofyan S., Willis. Konseling Keluarga, Bandung: Alfabeta. 2011.

Sugiyono. Metode Penelitian (Kuantitatif, Kualitatif, dan R dan D). Bandung: Alfabeta, 2016.

Syukur, Amin. Pengantar Setudi Sslam, Semarang: CV. Bima Sakti, 2003. 